\title{
STEM CELLS OF ADULT ORGANISMS IN BIOLOGY AND MEDICINE
}

\author{
Jerzy KAWIAK \\ Medical Center of Postgraduate Education, Warsaw, Poland
}

DOI: $10.2478 / \mathrm{v} 10052-010-0009-3$

Summary: The life span of adult cells is restricted, becoming senescent and eventually undergoing apoptosis. Cells are replaced by new ones which originate from a population of stem cells. An example is provided by the hemopoietic system in the bone marrow. In an adult body, stem cells may be identified by markers present in both embryonic and tissue-specific stem cells. Oct3/4, CXCR4, Nanog, CD133 and CD34 are examples of such markers. The stem cells share several properties, such as they may: 1) replicate and give rise to new stem cells, 2) differentiate into heterogenous tissue and organ specific cells and, finally, 3) stem cells are self-protected against various toxic agents and radiation. In adult tissues, stem cells reside in specialized sites (niches), for example in the bone marrow, skin, digestive tract epithelium, and skeletal muscles. Stem cells residing in these stem cell niches are anchored there by chemokines and adhesion molecules. Stroma-Derived Factor-1 (SDF-1), $\alpha$-chemokine and stem-cell expressed receptor CXCR4 play an important role in the retention of stem cells in such niches. Several stress factors may attenuate the SDF-1-CXCR4 axis in the bone marrow, which leads to the release of stem cells from their niches into circulation. Another important stem cell niche-anchoring mechanism is the interaction of Wnt (a ligand) with Frizzled LRP (receptor). The recently accumulated evidence suggests that malignancy arises from an arrest in maturation and mutation of stem cells. Cancer stem cells are responsible for tumor growth, its relapse and metastasis. The first direct evidence for the existence of cancer stem cells came from observations of acute myeloblastic leukemia. Currently, cell populations enriched for cancer stem cells have been isolated from several tumors. The cancer stem cells represent less than $1 \%$ of tumor cells in the mouse models.

Key words: stem cells, cancer stem cells, markers, mouse models, niches

\section{INTRODUCTION}

The body of an adult human consists of $10^{13}$ to $10^{15}$ cells [2]. The life span of individual cells varies but remains restricted and has been determined for some types of cells [17]. Dying cells become substituted by new ones, which originate 
and differentiate from tissue stem cells which circulate in the blood. The system of hemopoietic stem cells (HSC) in bone marrow represents one of the better recognized systems of cell reproduction from stem cells [25]. In Polish literature, the term "komórki macierzyste" (stem cells) was suggested for maternal cells of the hemopoietic system by W.W. Jędrzejczak in 1989 [25]. The terms related to the stem cells and their definitions are presented in Table 1.

TABLE 1. Definitions of terms used in stem cell description (according to [19], modified)

\begin{tabular}{|c|c|c|}
\hline NAME & DESCRIPTION & EXAMPLE \\
\hline Stem Cell & $\begin{array}{l}\text { Long-living cell, able to } \\
\text { reproduce, proliferate and } \\
\text { differentiate }\end{array}$ & VSELs \\
\hline Tissue Stem Cell & $\begin{array}{l}\text { Long-living cell, able for } \\
\text { reproduce, proliferate and } \\
\text { differentiate within the tissue }\end{array}$ & Hemopoietic stem cell \\
\hline Progenitor Cell & $\begin{array}{l}\text { Cell able to proliferate, giving } \\
\text { at least one generation }\end{array}$ & Neuroendocrine lung cells \\
\hline Cancer Stem Cell & $\begin{array}{l}\text { Cancer cell with high } \\
\text { regenerative potential and drug } \\
\text { resistance, renewing growth of } \\
\text { the cancer }\end{array}$ & Acute Myeloid Leukemia \\
\hline
\end{tabular}

\section{PROPERTIES OF STEM CELLS AND SUGGESTIONS FOR THERAPY}

In several tissues of the adult body infrequent cells have been identified, that manifest expression of protein-markers observed in cells of embryonic inner cell mass [44, 54, 61] (Table 2). These cells were isolated and examined closely in vitro and were termed stem cells. Hemopoietic stem cells (HSC) in the bone marrow of adult individuals, as well as in developing embryos carry the surface protein marker, CD $34^{+} \mathrm{CD} 38^{-}$[15]. Peripheral blood contains few HSC, however the umbilical blood, in contrast, contains numerous stem cells released from the bone marrow during the stress of parturition. These cells may be isolated from the placenta and umbilical cord, from tissues discarded following delivery. The HSC obtained from the umbilical blood may subsequently be used in children to restore the hemopoietic system or administered to patients who had lost blood in an accident or during surgery [4]. Together with the buffy coat white blood cells (WBC), these cells are also administered to patients following intense treatment with antineoplastic drugs, which damage production of leukocytes, erythrocytes and blood platelets. Stem cells originating from bone marrow, umbilical blood and various other organs of mice and humans, have been described in detail providing their morphological traits and presence of marker proteins [32, 33, 49, 67]. These cells are very small, with only a 3-5 $\mu \mathrm{m}$ diameter in mice, and carry markers of 
embryonic cells, and were named, Very Small Embryonic-Like cells (VSELs). VSELs have been identified in various tissues of adults and their number has been found to decrease with age of the body [68]. The hypothesis was put forward that following embryonic life, VSELs are preserved in the bone marrow as a mobile population of circulating precursor cells. They may play an important role in the postnatal replacement of both hemopoietic and non-hemopoietic cells.

TABLE 2. Stem cell markers on human bone marrow cells, also present on embryonic stem cells ([49], modified)

\begin{tabular}{|c|c|}
\hline CELLS & MARKERS \\
\hline Progenitor endothelial cells & CD133, CD34, CD31, CD117=c-kit \\
\hline Mesenchymal stem cells (MSC) & CD105, CD133, CD90 \\
\hline $\begin{array}{c}\text { Very Small Embryonic-Like stem cells } \\
\text { (VSELs) }\end{array}$ & CD133, CD34, Oct3/4, SSEA-4 \\
\hline
\end{tabular}

In the bone marrow and in other tissues, stem cells of endothelium also manifest the expression of the CD34 protein. A subpopulation cultured in vitro in the presence of several factors, including basic Fibroblast Growth Factor (bFGF), Insulin-like Growth Factor-1 (IGF-1) and Vascular Endothelial Growth Factor (VEGF) differentiated to become endothelial cells. Apart from the presence of the CD34 marker, the cells may be distinguished by their content of von Willebrand's factor (vWF) and by their incorporation of Low Density Lipoprotein (LDL). In order to discover whether endothelial precursor cells are permanently present in circulation and originate from bone marrow in vivo, bone marrow grafts have been performed between genetically distinct dogs [55]. DNA was analyzed in cells forming new blood vessels, originating from precursor CD34+ cells of bone marrow transplanted from another dog. The endothelial cells were found to originate from circulating cells of the graft recipient. As early as 1971 [29], following a heart transplantation, endothelial cells of human coronary arteries were shown to originate from recipient of the graft and not from the donor. Thus, it may be concluded that the dying endothelial cells of donor's heart are substituted by circulating precursor cells of the recipient.

Neural stem cells provide a potential source of cells for the treatment of neurodegenerative disease. Precursors of nestin-positive cells were found in cultures from skin biopsies or adipose tissue cells in the presence of FGF2 (Fibroblast Growth Factor2) and EGF (Epithelial Growth Factor) [62]. Nestin represents a marker of neuronal cells. Other authors [26] reported that they obtained nestin positive cells from adult skin biopsy following an in vitro culture in appropriately selected conditions. The original material contained no nestin positive cells.

Various sources of Mesenchymal Stem Cells (MSC) were compared [13] with the aim to obtain osteogenic material for bone reconstruction. MSC from adipose tissue proved to be of little advantage to the in vivo production of osteogenic tissue, but MSC originating from bone marrow or periosteum proved to 
be useful for the purpose [21]. In the experiments, alkaline phosphatase and osteocalcin were used as markers of the osteogenic differentiation.

In other in vitro experiments, the ability of MSC from bone marrow and from adipose tissue to differentiate to hepatocytes was compared [59]. A similar potential for differentiation was observed in cells from either source which may promote further attempts to use autologous cells of adipose tissue to support liver function. However, in a recently published report [13] MSC of human bone marrow could not differentiate to hepatocytes even though they could do so to osteoblasts, chondrocytes, adipocytes and vascular smooth muscle cells.

The physiological properties of stem cells have been similarly described by several authors. The descriptions explain the behavior of the cells in normal tissues of an adult individual as well as in pathologically altered tissues. The principal properties of stem cells include: a) their ability to reproduce: the stem cell may yield a new stem cell although frequency of such divisions is low, b) their ability to differentiate to tissue/organ cells: during the process the cells undergo numerous divisions yielding several differentiated cells, c) resistance to noxious factors, such as toxins and radiation. The latter property protects the stem cells, allowing them to survive in conditions which are lethal to other cells. The cell's resistance to toxins is explained by their ability to eliminate toxins from the cytoplasm, which may be evaluated using cytometry. For example, stem cells have been shown to eliminate one of the fluorescent stains from their cytoplasm, Hoechst 33342 . They may easily be distinguished from other cells, using flow cytometric graphs where they are separated from the main cell mass forming the so-called side population (SP) of cells $[15,23]$. The ABC transporters system represents the molecular determination of such behavior in the cells [58].

\section{CHEMOKINE SYSTEMS AND NICHES OF STEM CELLS}

Stem cells of the body reside in specific sites termed tissue or organ niches. The cells are maintained in the niches by chemokine systems. One of them involves the SDF-1 (Stromal Derived Factor-1), ligand system with a respective CXCR4 receptor on stem cells. The receptor is not evenly distributed on the cell surface, but is incorporated within the so-called rafts in the cell membrane [65]. SDF-1 is produced by stromal cells in, e.g. bone marrow and it modulates adhesion to fibronectin. The cells not permanently attached to their sublayer and carrying the appropriate receptor are maintained in sites in which SDF-1 is accumulated. The system is thought to retain hematopoietic stem cells and other cells with a CXCR4 receptor in the niche of bone marrow [64]. In the niche, the system controls intercellular signaling through changes in the ligand concentration and expression of the CXCR4 receptor. The system also preconditions the release of cells under 
the effect of regulating factors, such as G-CSF, and toxins or drugs, e.g. cyclophosphamide, or body stress factors like during childbirth or myocardial infarction [63]. In such situations stem cells are released from the niche and penetrate peripheral blood, in this way being able to reach the damaged sites, requiring repair. In experimental conditions, blocking of the SDF-1/CXCR4 system by administration of the AMD3100 inhibitor, inhibits interactions between the ligand and the receptor and HSC are expelled from bone marrow [13, 16, 22, 36].

Another chemokine system which is active in stem cell niches and important for the retention of cells involves the Wnt system [37, 50]. Families of Wnt glycoproteins are secreted and transmit signals in numerous biological processes during embryogenesis and organogenesis [48]. The proteins serve as ligands while their receptors in cell membranes of target cells involve complexes of G Frizzled protein, linked to LRP (Low density lipoprotein Receptor-related Protein). The Frizzled receptor proteins are anchored by seven domains in the cell membrane. LRPs of receptor complexes represent a family of proteins in humans including around 20 various molecules. Signaling through the Wnt system is conserved and of key importance for the control of cellular interactions during embryogenesis [8] and in an adult body [9]. In adult tissues the system provides signaling which controls the passage of cells along the epithelium, which may be of interest in the present context relating to the control of cell niches.

It is worth recalling that various niches of stem cells exist. Hemopoietic stem cells (HSC) in the bone marrow niche may be cytochemically distinguished by presence on the surface of the CD34 protein and of CXCR4 receptors [15]. Some HSC remain as well in circulation, accounting for around $0.1 \%$ of leukocytes in human peripheral blood. The number of circulating HSC become several fold amplified under the effects of toxic agents, such as some antineoplastic drugs. The release of HSC from the bone marrow niche currently represents a standard technique in transplant surgery, where traditionally the bone is punctured to obtain bone marrow with its associated HSC to use for grafting [35]. The donor instead is treated with either cyclophosphamide, G-CSF or both agents to release HSC in circulation. In such a situation stem cells are removed from the bone marrow and can be sampled from peripheral blood and administered to the patient in a dose related to their body weight [4].

Stem cells of the small intestine are located at the bottom of the intestinal glands. Every intestinal gland has between four and six stem cells, which can be identified by the expression of an Lgr5 gene, detected using in situ hybridization [5]. Some stem cells at the bottom of intestinal glands begin differentiation by frequent divisions as they pass toward the top of the gland, which is associated with further differentiation. The population of rapidly proliferating cells can be determined by taking advantage of proliferation markers (Ki67, BdrU) as well as by their expression of the $W d r 43$ gene. As the cells pass toward the opening of the gland and then to the intestinal villi, the cells differentiate up to three types, 
becoming enterocytes, goblet cells and neuroendocrine cells. In the bottom of the glands a fourth type of differentiated cells, the Paneth cells remain, which can be distinguished morphologically and by their expression of a Defa 1 gene. Stem cells of the large intestine, with their niche in the bottom of the Lieberkühn glands, behave similarly $[12,43,51]$. These cells may also be distinguished by their expression of the Lgr5 gene [5]. Cells in the base of the gland seldom divide but begin differentiation with frequent divisions. These cells differentiate into enterocytes and goblet cells, but stop dividing at opening of the gland as they pass to the epithelium surface, where they undergo apoptosis and desquamation.

Epidermal stem cells have their niches in hair follicle bulges, situated approximately in the middle of the height of the follicle. These cells can be distinguished by their expression of a CD200 marker [6, 45]. From this region, the differentiating cells follow cell divisions as they translocate toward the sebaceous gland and to the surface of the skin, forming the epidermis. Other stem cells translocate in the opposite direction, toward the hair bulb, from which the hair shaft originates. The bulge represents an relative immune privilege site [41]. The respective cells manifest the low expression of MHC class I and class II antigens and of $\beta 2$-microglobulin, as well as a high expression of immunosuppressive factors, such as TGF $\beta 2$, the factor which inhibits macrophage migration.

\section{ORIGIN OF TISSUE STEM CELLS AND REPROGRAMMING OF DIFFERENTIATED CELLS}

The origin of stem cells present in an adult body is not obvious. The principal evidence for their presence in the body tissues and organs involves the presence of marker proteins in the cells, which are also expressed by cells within the inner cell mass in the early period of life $[44,54,61]$. Therefore, the cells might represent remnants of the embryonic cells, which persist and divide in an adult body.

In the course of normal embryo development, developmental potential of embryonic cells decreases. As mentioned above, adult body and fetal membranes contain cells of a multipotential character, tissue stem cells (Table 1). The very small embryonic-like (VSEL) cells [33] express marker proteins in adult life, who are present also in cells of the inner cell mass during the blastula stage [44, 61]. The markers include alkaline phosphatase, SSEA-1, Oct4, Nanog. With progressing age of mammals a decrease in tissue stem cell number was noted [67], which might indicate exhaustion of the stem cell pool in senescent individuals.

Recent attempts have been made to obtain pluripotent cells from somatic cells as a result of their reprogramming $[10,40,56]$. The molecular mechanisms of such a process have not been recognized in detail. A reprogramming in mouse and 
human somatic cells was attempted using four transcription factors, with the aim of transforming a small subpopulation into pluripotent cells, similar to embryonic stem cells [38]. The studies were conducted on various somatic cells, including mouse fibroblasts transfected in vitro with a vector(s) transmitting cDNA of Oct4, Sox2, $c-M y c$ and Klf4 genes [40]. The reprogrammed cells were termed iPS cells (induced Pluripotent Stem cells). These were capable of differentiation into cells of three germ layers, and also to gametes in chimeric mice [46]. Analysis of DNA methylation and histone modification suggests that chromatin of mouse iPS cells was reprogrammed to the embryonic condition. This pertained to the demethylation of endogenous promoters which control specific Nanog and Oct4 genes. The sequence of activation was also examined for the four principal factors, previously identified as indispensable for reprogramming of mouse fibroblasts (Table 3) [7]. Expression of SSEA1 following the expression of alkaline phosphatase was found to represent an intermediate condition, which must be supported to enable the subsequent expression of Oct4 and Nanog genes. Activation of endogenous Oct4 and Nanog may represent a condition during direct reprogramming in iPS cells, already independent on additional active genes. It was also noted that some stem cells in tissues express already some transcription factors which are of key importance to reprogramming. In such situations, neural progenitor cells can be reprogrammed using the two factors, Oct4 and Klf4 [30], or even via the factor Oct4 only.

The reprogramming systems were studied for very different somatic cells: lymphocytes B [20], skin cells [26], and human keratinocytes [1]. It was also determined that the parallel inhibition of Mitogen-Activated Protein Kinase (MAPK) and of Glycogen Synthase Kinase-3 (GSK3), in conjunction with a renewed expression of Leukemia Inhibitory Factor (LIF) directed pre-pluripotent cells to full pluripotency [56].

TABLE 3. Reactivation of pluripotential markers in reprogrammed mouse fibroblasts in vitro (according to the description of Brambrink et al. [7])

\begin{tabular}{|c|c|c|c|c|}
\hline $\begin{array}{c}\text { Day of } \\
\text { induction }\end{array}$ & $\begin{array}{c}\text { Alkal.phosphatase } \\
\text { \% positive cells }\end{array}$ & $\begin{array}{c}\text { SSEA1 } \\
\text { \% positive cells }\end{array}$ & $\begin{array}{c}\text { Nanog } \\
\text { \% positive cells }\end{array}$ & $\begin{array}{c}\text { Oct4 } \\
\text { \% positive cells }\end{array}$ \\
\hline 3 & $3-4$ & 0 & 0 & 0 \\
\hline 9 & 28 & 4 & 0 & 0 \\
\hline 12 & 38 & 9 & 0 & 0 \\
\hline 16 & 38 & 9 & 0.2 & 0.2 \\
\hline 26 & 82 & 11 & 2 & 2 \\
\hline 35 & 76 & 16 & 3 & 3 \\
\hline
\end{tabular}




\section{CANCER STEM CELLS}

The progress in tumor therapy has markedly extended the life of many patients. Nevertheless, medical practice indicates that in several cases the originally favorable result of the therapy frequently is followed by a relapse of the tumor and, in cases of solid tumors, by metastases. Evidence suggests that the growth and spread of several tumors depends on a small subpopulation of cells in the tumor, termed the cancer stem cells $[24,27]$. According to this view, a tumor represents not only a monoclonal growth of transformed cells, but also a complex tissue, in which the abnormal growth is powered by few pathologically altered stem cells. The altered cells manifest traits such as uncontrolled growth and an ability to form metastases, but also are able to preserve the ability for self-renewal and differentiation into a phenotypically variable progeny. This view is supported by experimental observations on cells of human acute myeloid leukemia (AML). In 1994, Lapidot et al. [34] documented the presence of leukemic stem cells in acute myeloid leukemia by cloning the cells and observing their ability for self-renewal. Cells of the $\mathrm{CD} 34^{+} \mathrm{CD} 38^{-}$subpopulation were sorted and separated from the patient's (suffering from acute leukemia) peripheral blood. Upon injection into SCID mice, these cells were able to initiate leukemia even if, $\mathrm{CD} 34^{+} \mathrm{CD} 38^{+}$or CD34 patient cells manifested no such activity. SCID mice have inherited immunodeficiency and therefore do not reject xenografts of human cells. The cells of leukemia developing in mice may be transplanted to the other SCID mice, suggesting the implanted cells primarily carry the ability for self-renewal. Such observations of leukemia cells as those related to their self-renewal and to their relapsed growth following the transfer of individual leukemia cells to another mouse are accepted as principal criteria for the recognition of cancer stem cells ("gold standard"). Similar cancer stem cells or cancer initiating cells were identified not only in AML but also in solid tumors [3, 14, 18, 19, 47, 51, 57]. Tumor cell lines were found to contain cancer stem cells $[28,31]$ as well. The concept of the existence of cancer stem cells or cancer initiating cells may significantly affect the therapy options aimed at the complete eradication of tumors in a patient.

It is difficult to establish how cancer stem cells or initiating cells may arise. The frequency of spontaneous mutations is estimated at $10^{-6}$ to $10^{-7}$ mutations per gene per cell division [2]. In a human body, around $10^{16}$ cell divisions are estimated during a lifetime and thus, every human gene has the chance to undergo mutation more than $10^{9}$ times. Most frequently the mutations are effectively repaired in the cell or the cells with mutated genes are eliminated by the immune system.

In a similar way to the genome of differentiated cells, oncogenic mutations may occur in stem cells. Upon the characterization of such cells, some of their traits are considered: a) the ability for self-renewal but infrequent divisions; the 
effect of prolonged interkinesis includes the chance of the accumulation of mutations in the same cell leading to features typical to cancer cells, b) the ability to differentiate to tissue or organ cells; the primary tumor may consist of differentiated cells while the cancer stem cells comprise a small population only; in experimental conditions cancer cell lines may be different however, and many cells may carry traits of stem cells due to selection as it happens, e.g., in the case of L1210 mouse leukemia cells [28], c) resistance to noxious agents reflecting the fact that cancer stem cells demonstrate a high expression of multidrug resistance-related proteins $[39,58]$.

In this context, however, it is still worth stressing some of the other traits of cancer stem cells, like the expression of antigens typical to embryonic stem cells, such as Oct3/4, SSEA-1 or SSEA-4, CD133, CD90, the ability to repair DNA [42], and the decreased potential to initiate apoptosis. Among cells isolated from primary tumors and from cancer cell lines, the already mentioned cells of the "side population" (SP) were detected, being populations of cells which eliminate Hoechst 33342 dye from their cytoplasm. It is assumed that, similar to elimination of the dye, SP cells may also eliminate drugs used in therapy $[15,23]$. In fact, the sorted SP cells were demonstrated to support tumor growth after their implantation in mice. SP cells were also demonstrated to exhibit a high expression of the multidrug resistance-related proteins including the Multi Drug Resistance Transporter-1 (MDR-1) [11] and BCRP-1 (Breast Cancer Resistance Protein-1), although no correlation could be detected between the number of SP positive cells and the number of MDR-1 $1^{+}$cells in patients with AML. Various authors have published review articles and experimental reports relating to attempts at therapy targeting cancer stem cells $[11,43,52,53,60,66]$. At present, this trend of therapy seems to be most reasonable.

\section{ACKNOWLEDGEMENT}

The preparation of the paper was supported by European Union structural funds, Innovative Economy Operational Programme, grant no. POIG 01.02-00-109/09 "Innovative methods of stem cells applications in medicine".

\section{REFERENCES}

[1] AASEN T, RAYA A, BARRARO MJ et al. Efficient and rapid generation of induced pluripotent stem cells from human keratinocytes. Nature Biotechnol 2008; 26: 1276-1284.

[2] ALBERTS B, BRAY D, HOPKIN K et al. Essential Cell Biology, 2005 PWN.

[3] AL-HAJJ M, CLARKE MF. Self-renewal and solid tumor stem cells. Oncogene 2004; 23: 7274-7282. 
[4] ALLAN DS, KEENEY M, HOWSON-JAN K et al. Number of viable CD34 ${ }^{+}$cells reinfused predicts engrafment in autologous hemopoietic stem cell transplantation. Bone Marrow Transplant 2002; 29: 967-972.

[5] BARKER N, van ES JH, KUIPERS J et al. Identification of stem cells in small intestine and colon by marker gene Lgr5. Nature 2007; 449: 1003-1007.

[6] BLAUPLAIN C, LOWRY WE, GEOGHEGAN A et al. Self-renewal, multipotency and the existence of two cell populations within an epithelial stem cell niche. Cell 2004;118: 635-648.

[7] BRAMBRINK T, FOREMAN R, WELSTEAD GG et al. Seguential expression. of pluripotency. markers during direct reprogramming of mouse somatic cells. Cell Stem Cell 2008; 2: 151-159.

[8] CADDIGAN KM, NUSSE R. Wnt signaling: a common theme in animal development. Genes Dev 1997; 11: 3286-3305.

[9] CHENG JH, SHE H, HAN Y-P et al. Wnt antagonism inhibits hepatic stellate cell activation and liver fibrosis. Am J Physiol Gastrointest 2008; 294: G39-G49.

[10] CIEMERYCH MA. Embryonic stem cells - searching for the pluripotency. Post Biol Komorki 2008; 35: 183-205.

[11] COLLINS AT, BERRY PA, HYDE C et al. Prospective identification of tumorogenic prostate cancencer. stem cells. Cancer Res 2005; 65: 10946-10951.

[12] [DALERBA P, DYLLA SJ, PARK IK et al. Phenotypic characterization of human colorectal cancerstem cells. Proc Natl Acad Sci US 2007; 104: 10158-10163.

[13] DELORME B, RINGE J, PONTIKOGLOU C et al. Specific lineage-priming of bone marrow. mesenchymal stem cells provides the molecular framework for their plasticity. Stem Cells $2009 ; 2 \overline{7}$ $1142-1151$.

[14] FANG D, NGUYEN TK, LEISHEAR K et al. A tumorigenic subpopulation with stem stem cell properties. in melanomas. Cancer Res 2005; 65: 9328-9337.

[15] FEURING-BUSKE M [10], HOGGE DE. Hoechst 33342 efflux identifies a subpopulation of cytogenetically normal $\mathrm{CD} 34^{+} \mathrm{CD} 38^{-}$progenitor cells from patients with acute myeloid leukemia. Blood 2001; 97: 3882-3889.

[16] FLOMENBERG N, DEVINE SM, DIPERSIO JF et al. The use of AMD3100 plus G-CSF for autologous hemopoietic progenitor cell mobilization is superior to G-CSF alone. Blood 2005; 106: 1867-1874.

[17] FURNE JK, SPRINGFIELD JR, HO SB, LEVITT MD. Simplification of the end-alveolar carbon monoxide technique to assess erythrocyte survival. J Lab Clin Med 2003; 142: 52-57.

[18] GIBBS CP, KUKEKOV VG, REITH JD et al. Stem-like cells in bone sarcomas: implications for tumorigenesis. Neoplasia 2005; 7: 967-976.

[19] GLANGRECO A, GROOT KR, JANES SM. Lung cancer and lung stem cells. Strange bedfellows? Am J Respir Crit Care Med 2007; 175: 547-553.

[20] HANNA J, MARKONLAKI S, SCHOERDRET P et al. Direct reprogramming of terminally differentiated mature B lymphocytes to pluripotency. Cell 2008; 133: 250-261.

[21] HAYASHI O, KATSUBE Y, HIROSE M et al. Comparison of osteogenic ability of rat mesenchenymal stem cells from bone marrow, periosteum and adipose tissue. Calcif Tissue Int 2008; 82: 238-247.

[22] HESS DA, BONDE J, CRAFT TC et al. Human progenitor cells rapidly mobilized by AMD3100 repopulate NOD/SCID mice with increased frequency in comparison to cells from the same donor mobilized by G-CSF. Biol Blood Marrow Transpl 2007; 13: 398-411.

[23] HIRSCHMANN-JAX C, FOSTER AE, WULF GG et al. A distinct "side population" of cells with high drug efflux capacity in human tumor cells. Proc Natl Acad Sci US 2004; 101: 14228-14233.

[24] HOPE KJ, JIN L, DICK JE. Accute myeloid leukemia originates from a hierarchy of leukemic stem cell. classes that differ in self-renewal capacity. Nature Immunol 2004; 5 : 738-743.

[25] JEDRZEJCZAK WW. Proposition of polish nomenclature in experimental hematology. in Ultrastructure and function of cell, ed. Kawiak J, Osuchowska Z, Przełęcka A, vol.3, PWN, Warsaw 1989.

[26] JOANNIDES A, GAUGHWIN P, SCHWIENING C et al. Efficient generation of neural precursors from adult human skin: astrocytes promote neurogenesis from skin-derived stem cells. Lancet 2004; 364: 172-178.

[27] JORDAN CT, GUZMAN ML, NOBLE M. Cancer stem cells. N Engl J Med. 2006; 355: 1253-1261. 
[28] KAWALEC M, SKORSKI T, KAWIAK J. Successful chemoimmunotherapy of murine L1210 lymphatic leukemia with cyclophosphamide and mafosfamide-treated leukemia cells. Invest New Drugs 1988; 6: 169-172.

[29] KENNEDY LJ, Jr, WEISSMAN IL. Dual origin of intimal cells in cardiac-allograft arteriosclerosis. New Engl J Med 1971; 285: 884-887.

[30] KIM JB, ZAEHRES H, WU G et al. Pluripotent stem cells induced from adult neural stem cells by reprogramming with two factors. Nature 2008; 454: 646-650.

[31] KONDO T, SETOGUCHI T, TAGA T. Persistence of small subpopulation of cancer stem-like cells in the C6 glioma cell line. Proc Natl Acad Sci US 2004; 101: 781-786.

[32] KUCIA M, HALASA M, WYSOCZYNSKI M et al. Morphological and molecular characterization of novel population of CXCR $4^{+}$SSEA- $-4^{+}$Oct- $4^{+}$very small embryonic-like cells purified from human cord blood - preliminary report. Leukemia 2007; 21: 297-303.

[33] KUCIA M, RECA R, CAMPBELL FR et al. A population of very small embryonic-like (VSEL) CXCR $4^{+}$SSEA- $1^{+}$Oct- $4^{+}$stem cells identified in adult bone marrow. Leukemia 2006; 20: 857-869.

[34] LAPIDOT T, SIRARD C, VORMOOR J et al. A cell initiating human acute myeloid leukemia after transplantation into SCID mice. Nature 1994; 367: 645-648.

[35] LEVESQUE JP, HENDY J, TAKARNATSU Y et al. Disruption of the CXCR4/CXCL12 chemotactic interaction during hematopoietic stem cell mobilization induced by G-CSF or cyclofosfamide. J Clin Invest 2003; 111: 187-196.

[36] LILES WC, RODGER E, BROXMEYER HE et al. Augumented mobilization and collection of $\mathrm{CD} 4^{+}$hemopoietic cells from normal human volunteers stimulated with G-CSF by single-dose administration of AMD3100, a CXCR4 antagonist. Transfusion 2005; 45: 295-300.

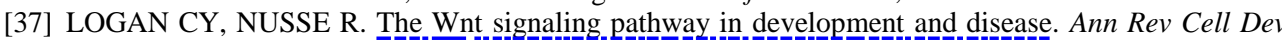
Biol 2004; 20: 781-810.

[38] LOH YH, AGRAVAL S, PARK IH et al. Generation of induced pluripotent stem cells from human blood. Blood 2009; 113: 5476-5479.

[39] LOU H, DEAN M. Targeted therapy for cancer stem cells: the patched pathaway and and ABC trangansporters. Oncogene 2007; 26: 1357-1360.

[40] MEISSNER A, WERING M, JAENISCH R. Directt reprogramming of genetically unmodified. fibroblasts into pluripotent stem cells. Nature Biotechnol 2007; 25: 1177-1181.

[41] MEYER KC, KLATTE JE, DINH HV et al. Evidence that the bulge region is a site of relative immune privilege in human hair follicles. Br J Dermatol 2008; 159: 1077-1085.

[42] NOWACKA-ZAWISZA M, KRAJEWSKA WM. The role of BCRA1, BCRA2 and RAD51 proteins in the maintenance of genome stability. Post Biol Komorki 2009; 36: 679-694.

[43] O'BRIEN CA, POLLET A, GALLINGER S, DICK JE. A human colon cancer cell capable of initiating tumor growth in immunodeficient mice. Nature 2007; 445: 106-110.

[44] O'CONNOR MD, KARDEL MD, IOSFINA I et al. Alkaline phosphatase-positive colony formation is a sensitive, specific, and quantitative indicator of undifferentiated human embryonic stem cells. Stem Cells 2008; 26: 1109-1116.

[45] OHYAMA M. Advances in the study of stem cell-enriched hair follicle bulge cells: a review featuring characterization and isolation of human bulge cells. Dermatology 2007; 214: 342-351.

[46] OKITA K, ICHISAKA T, YAMANAKA S. Generation of germline-competent induced pluripotent stem cells. Nature 2007; 448: 313-317.

[47] PATRAWALA L, CALHOUN T, SCHNEIDER-BROUSSARD R et al. Highly purified CD44 prostate cancer cells from xenograft human tumors are enriched in tumorigenic and metastatic progenitor cells. Oncogene 2006; 25: 1696-1708.

[48] PATTHEY C, EDLUND T, GUNHAGA L. Wnt-regulated temporal control of BMP exposure directs the choice between neural plate border and epidermal fate. Development 2009; 136: 73-83.

[49] RATAJCZAK MZ, ZUBA-SURMA EK, MACHALINSKI B et al. Very small embryonic-like (VSEL) stem cells: purification from adult organs, characterization and biological significance. Stem Cell Rev 2008; 4: 89-99.

[50] REYA T, CLEVERS H. Wnt signalling in stem cells and cancer. Nature 2005; 434: 843-850.

[51] RICCI-VITIANI L, LOMBARDI DG, PILOZZI E et al. Identification and expression of human coloncancer-initiating cells. Nature 2007; 445: 111-115. 
[52] ROBEY RW, STEADMAN K, POLGAR O et al. Pheophorbide a is a specific probe for ABCG2 function and inhibition. Cancer Res 2004; 64: 1242-1246.

[53] ROBEY RW, TO KK, POLGAR O et al. ABCG2: a perspective. Adv Drug Deliv Rev 2009; 61: 3-13.

[54] ROSSANT J. Stem cells and early lineage development. Cell 2008; 132: 527-531.

[55] SHI Q, RAFII S, HONG-DEWU M et al. Evidence for circulating bone marrow-derived endothelial cells. Blood 1998; 92: 362-367.

[56] SILVA J, BARRANDON O, NICHOLS J et al. (2008) Promotion of reprogramming to ground state pluripotency by signal inhibition. PLoS Biol 6: e253.

[57] SINGH $\overline{\mathrm{SK}}, \mathrm{HA} \overline{\mathrm{WK}} \mathrm{IN} \overline{\mathrm{S}} \mathrm{C}, \mathrm{C} \overline{\mathrm{LARKE}}$ ID et al. Identification of human brain tumor initiating cells. Nature 2004; 432: 396-401

[58] SWERTS K, DEMOLERLOOSE B, DHOOGE $\mathrm{C}$ et al. Prognostic significance of multidrug resistance-related proteins in childhood acute lymphoblastic leukemia. Eur J Cancer 2006; 42: 295309.

[59] TALENS-VISCONTI R, BONORA A, JOVER R et al. Hepatogenic differentiation of human mesenchymal stem cells from adipose tissue in comparison with bone marrow mesenchymal cells. World J Gastroenterol 2006; 12: 5834-5845.

[60] TANG C, ANG BT, PERVAIZ S. Cancer stem cell: target for anti-cancer therapy. FASEB J 2007; 21: 3777-3785

[61] THOMSON JA, ITZKOVITZ-ELDOR J, SHAPIRO SS et al. Embryonic stem cell lines derived from human blastocysts. Science 1998; 282: 1145-1147.

[62] VINDIGNI V, MICHELOTTO L, LANCEROTTO L et al. Isolation method for a stem cell population with neural potential from skin and adipose tissue. Neurol Res 2009; publ ahad PMID15246730

[63] WOJAKOWSKI W, TENDERA M, MICHALOWSKA A et al. Mobilization of CD34/CXCR4 ${ }^{+}$ $\mathrm{CD} 34 / \mathrm{CD} 117^{+}$, c-met $^{+}$stem cells and mononuclear cells expressing early cardiac muscle and endothelial markers into peripheral blood in patients with acute myocardial infarction. Circulation 2004; 110: 3213-3220.

[64] WRIGHT DE, WAGERS AJ, GULATI AP et al. Physiological migration of hemopoietic stem and progenitor cells. Science 2001; 294: 1933-1936.

[65] WYSOCZYNSKI M, RECA R, RATAJCZAK J et al. Incorporation of CXCR4 into membrane lipid rafts primes doming-related responses of hematopoietic stem/progenitor cells to an SDF-1 gradient. Blood 2005; 105: 40-48

[66] YILMAZ OH, VALDEZ R, THEISEN BK et al. Pten dependence distinguishes hemopoietic stem cells from leukemia-initiating cells. Nature 2006; 441: 475-482

[67] ZUBA-SURMA EK, KUCIA M, ABDEL-LATIF A et al. Morphological characterization of very small embryonic-like stem cells (VSELs) by ImageStream system analysis. J Cell Mol Med 2008; 12 292-303.

[68] ZUBA-SURMA EK, WU W, RATAJCZAK J et al. Very small embryonic-like stem cells in adult tissues - potential implications for aging. Mech Ageing Dev 2009; 130: 58-66.

Corresponding author: Jerzy Kawiak

Medical Center of Postgraduate Education

99 Marymoncka Str., 01-813 Warsaw

e-mail adress: jkawiak@cmkp.edu.pl 